\title{
Pengembangan Blog Sebagai Media Pembelajaran Matematika
}

\author{
Aji Arif Nugroho', Rizki Wahyu Yunian Putra ${ }^{2}$, Fredi Ganda Putra ${ }^{3}$, M. Syazali ${ }^{4}$ \\ ${ }^{1}$ SMAN 1 Batanghari, Lampung: ajiarif@gmail.com \\ ${ }^{2,3,4}$ UIN Raden Intan Lampung
}

\begin{abstract}
This study aims to test the feasibility of media-based learning Blog in learning mathematics on trigonometric subjects. This development research uses 8 stages from 10 stages of borg and gall method that are potential and problem, data collection, product design, product validation, product revision, product test, product revision and mass production. Learning media blogs are developed with the help of adobe flash which aims to provide some animation. This research was conducted in SMA Negeri 1 Batanghari class $X$ students. The assessment instrument used was questionnaire of feasibility test by media expert, Expert of Material, and Questionnaire of student response. The results of the research are: 1) Based on the validation of material expert judgments obtained an average score of 4.65 is located in the category of "Very Good". Validation of expert media judgment obtained an average score of 4.35 in the category of "Very Good". Validation of the linguist's assessment obtained an average score of 4.5 that is in the category of "Very Good". In addition, the results of small-scale test responses of learners obtained a score of 4.23 on the criteria of "Very Good", and while on a large-scale test the learners' response to get an average score of 4, 19 is on the criteria of "Good". Thus it can be concluded learning media berbantuan blog is in good category and can be used in learning, especially on Trigonometry material.
\end{abstract}

Keywords: Blog Media; Instructional Media

\begin{abstract}
Abstrak
Penelitian ini bertujuan untuk menguji kelayakan media pembelajaran berbasis Blog dalam pembelajaran matematika pada pokok bahasan trigonometri. Penelitian pengembangan ini menggunakan 7 tahap dari 10 tahap metode borg and gall yaitu potensi dan masalah, pengumpulan data, desain produk, validasi produk, revisi produk, ujicoba produk, revisi produk dan produksi masal. Media pemebelajaran blog yang di kembangkan dengan bantuan adobe flash yang bertujuan untuk memberikan beberapa animasi. Penelitian ini dilakukan di SMA Negeri 1 Batanghari siswa kelas X. Istrumen penilaian yang digunakan adalah angket uji kelayakan oleh Ahli media, Ahli Materi, dan Angket respon siswa. Hasil penelitian adalah : 1) Berdasarkan validasi penilaian ahli materi diperoleh skor rata-rata 4,65 yaitu berada pada kategori "Sangat Baik". Validasi penilaian ahli media diperoleh skor rata-rata 4,35 yaitu pada kategori "Sangat Baik". Validasi penilaian ahli bahasa diperoleh skor rata-rata 4,5 yaitu berada pada kategori "Sangat Baik". Selain itu dari hasil uji coba skala kecil respon peserta didik memperoleh skor 4,23 yaitu pada kriteria "Sangat Baik", dan sedangkan pada uji coba skala besar respon peserta didik memperoleh skor rata-rata 4,19 yaitu pada kriteria "Baik". Dengan demikian dapat disimpulkan media pembelajaran berbantuan blog berada dalam kategori baik dan dapat digunakan dalam pembelajaran khususnya pada materi Trigonometri.
\end{abstract}

Kata Kunci:Media Blog ; Media Pembelajaran 


\section{PENDAHULUAN}

Berkembang dan majunya zaman dapat dilihat dengan banyak munculnya teknologi aplikasi-aplikasi komputer. Kemajuan ilmu pengetahuan dan teknologi menuntut seseorang untuk dapat menguasai teknologi informasi dan pengetahuan. Jaringan internet pun telah diluncurkan dan sudah banyak digunakan oleh masyarakat luas, yang seharusnya sudah bisa dimanfaatkan untuk menunjang kemajuan dalam dunia pendidikan khususnya dalam pembelajaran matematika agar semakin efektif dan efisien.

Matematika memiliki peranan yang penting karena sebagai dasar logika atau penalaran dan penyelesaian kuantitatif yang digunakan dalam pelajaran lainnya. Akan tetapi, masyarakat masih memandang tentang pelajaran matematika merupakan pelajaran yang sulit dan menakutkan (Putra, 2016). Mempelajari matematika tidak hanya memahami konsepnya saja atau prosedurnya saja, akan tetapi banyak hal yang dapat muncul dari hasil proses pembelajaran matematika. (Putra, 2017) Dalam belajar matematika peserta didik cenderung menghafal rumus, meniru contoh soal yang diberikan oleh guru, dan kurangnya siswa dalam memahami materi sehingga tiap kali diberikan soal matematika yang berbeda, peserta didik belum mampu mengerjakan soal tersebut, akibatnya kemampuan peserta didik masih tergolong rendah meskipun peserta didik telah diberikan buku pegangan matematika (Anggoro, 2015). Maka dengan hal ini perlunya ada inovasi-inovasi dalam rangka memanfaatkan teknologi komputer dan jaringan internet dalam pembelajaran matematika agar diharapkan pembelajaran matematika lebih efektif.

Berdasarkan permasalahan diatas dalam proses pembelajaran matematika memerlukan suatu alat bantu sebagai penunjang belajar tanpa harus berkutat dengan pembelajaran yang membosankan dikelas yang dipenuhi dengan tugas-tugas. Selain itu sering terjadinya penambahan jam pelajaran dikarenakan penyampaian materi tidak sesuai dengan alokasi waktu yang diberikan, maka sangat perlu sebuah media yang bisa dimanfaatkan oleh pendidik tanpa harus mengadakan jam tambahan disekolah seperti sebuah web atau blog pendidikan yang bisa dibaca dan dipelajari dimana saja. Blog memenuhi kriteria suatu media yang digunakan dalam pendidikan. Hal ini karena blog sangat fleksibel dalam penggunaannya karena dapat diakses kapanpun dan dimanapun (Fatmayanti, 2015)

Beberapa penelitian telah dilakukan dalam mengembangkan media pembelajaran blog dalam pembelajaran untuk mempermudah proses pembelajaran, sebagai upaya meningkatkan hasil belajar, sebagai sarana informasi, menanamkan karakter kritis dan kreatif dan sebagai penunjang dalam belajar. (Fajriah, Zulkardi, \& Siroj, 2017; Fatmayanti, 2015; Kustijono, 2012; Ratnasari \& Hamdan, 2015; Rhamandica, Wonorahardjo, \& Arief, 2016; Sunismi \& Fathani, 2017; Weni \& Isnani, 2016; Wijayanti \& Basyar, 2017). Namun, belum ada penelitian sebelumnya yang mengembangkan media pembelajaran blog untuk materi trigonometri.

Berdasarkan penelitian yang telah dilakukan sebelumnya, keterbaruan dalam penelitian ini terletak pada pengembangan media pembelajaran berupa blog untuk materi trigonometri kelas X. Maka, tujuan dari penelitian ini adalah mengetahui kelayakan media pembelajaran 
blog yang mudah dipahami untuk peserta didik dalam pembelajaran mata pelajaran matematika pada materi trigonometri

\section{METODE PENELITIAN}

Jenis penelitian yang digunakan dalam penelitian ini adalah $R \& D$ (Research and Development). Prosedur dalam penelitian ini menggunakan 8 tahap dari 10 tahap model Borg and Gall yaitu: 1) Observasi Analisis kebutuhan, 2) Pengumpulan Data, 3) Desain Produk, 4) Validasi Produk, 5) Revisi Produk, 6) Uji coba Produk, 7) Revisi Akhir, 8) Penyebarluasan (Sugiyono, 2010)

.Instrumen yang digunakan dalam pengumpulan data ini yaitu menggunakan lembar validasi, lembar observasi dan lembar angket. Data yang digunakan dalam penelitian dan pengembangan ini adalah data kualitatif dan data kuantitatif (Novalia \& Syazali, 2014). Teknik pengumpulan data dalam penelitian ini adalah dengan menggunakan angket. Pada dasarnya kuesioner adalah sebuah daftar pertanyaan yang harus di isi oleh orang yang akan diukur (responden). Dengan kuesioner ini dapat diketahui tentang keadaan/data diri, pengalaman, pengetahuan sikap atau pendapatnya dan lain-lain (Arikunto, 1984)

Rumus untuk menentukan jarak interval dari sangat kurang (SK) sampai sangat baik (SB) adalah :

$$
\bar{x}=\frac{\sum x}{n}
$$

Berdasarkan jarak interval di atas dapat disusun tabel kriteria sikap responden terhadap produk hasil dari pengembangan dan penelitian sebagai berikut:

Tabel 1. Interval Kevalidan

\begin{tabular}{|c|c|c|}
\hline Rata-rata skor $(\bar{x})$ & Klasifikasi & Kesimpulan \\
\hline $\bar{x}>4,2$ & Sangat baik & Dapat dijadikan contoh \\
\hline $3,4<\bar{x} \leq 4,2$ & Baik & Dapat digunakan tanpa perbaikan \\
\hline $2,6<\bar{x} \leq 3,4$ & Cukup & Dapat digunakan dengan sedikit perbaikan \\
\hline $1,8<\bar{x} \leq 2,6$ & Kurang & Dapat digunakan dengan banyak perbaikan \\
\hline $\bar{x} \leq 1,8$ & Sangat kurang & Belum dapat digunakan \\
\hline
\end{tabular}

\section{HASIL PENELITIAN DAN PEMBAHASAN}

Hasil utama penelitian dan pengembangan ini adalah media pembelajaran berbantuan Blog pada materi trigonometri. Penelitian ini menggunakan 8 tahap dari 10 tahap model Borg and Gall yang sudah dimodifikasi oleh Sugiyono. Hasil penilaian kelayakan media pembelajaran berbantuan Blog ini dapat dilihat pada Tabel 2 sebagai berikut : 
Tabel 2. Hasil penilaian kelayakan produk media pembeajaran berbantuan blog

\begin{tabular}{cccccc}
\hline $\begin{array}{c}\text { Hasil rata-rata } \\
\text { validasi }\end{array}$ & \multicolumn{2}{c}{ Ahli Media } & \multicolumn{2}{c}{ Ahli Materi } & Ahli Bahasa \\
& $\begin{array}{c}\text { Validator } \\
\text { 1 }\end{array}$ & Validator 2 & Validator 1 & Validator 2 & Validator 1 \\
\cline { 2 - 5 } & 4,7 & 4,6 & 4,2 & 4,5 & 4,5 \\
Rata-rata skor & & 4,65 & 4,35 & 4,5 \\
Kriteria & Sangat Baik & Sangat Baik & Sangat Baik \\
\hline
\end{tabular}

Berdasarkan hasil tabel diatas dapat dilihat bahwa pada aspek media diperoleh nilai 4,7 dari validator 1 dan diperoleh nilai 4,6 dari validator 2 sehingga hasil rata-rata yang diperoleh dari ahli media mencapai angka 4,65 hal ini berarti media pada kriteria sangat baik. Hasil aspek materi diperoleh nilai 4,2 dari validator 1 dan diperoleh nilai 4,5 dari validator 2 sehingga skor rata-rata yang diperoleh oleh ahli materi mencapai angka 4,35 pada kriteria sangat baik, sedangkan pada aspek bahasa diperoleh nilai 4,5 dari validator 1 sehingga hasil skor rata-rata yang diperoleh dari ahli bahasa yaitu 4,5 pada kriteria sangat baik. Media pembelajaran berbantuan blog oleh para validator dapat di simpulkan memiliki kriteria kelayakan yang sangat baik. Hasil ini tidak terlepas dari saran dan masukan oleh validator. Dari kriteria kelayakan media blog tersebut maka hasil produk media blog dapat di lanjutkan untuk uji coba lapangan.

Uji coba lapangan dilakukan disekolah SMA Negeri 1 Batanghari siswa kelas X. Uji coba lapangan dilakukan pada uji skala kecil dan uji skala besar.

a. Uji coba skala kecil

Uji coba skala kecil dilakukan pada peserta didik kelas X IPA SMAN 1 Batanghari sebanyak 10 peserta didik. Responden melakukan penilaian terhadap media pembelajaran berbantuan blog yang ditampilkan, kemudian mengisi kuesioner isian yang sudah disediakan. Tahap uji yang dilakukan yaitu untuk melihat bagaimana respon siswa/i terhadap media pembelajaran blog yang dikembangkan sebagai salah satu media yang digunakan siswa/i dalam proses pembelajaran matematika di kelas X SMAN 1 Batanghari. Hasil uji coba skala kecil yaitu dalam kategori baik dengan hasil 4,233.

b. Uji coba skala besar

Uji coba skala besar dilaksanakan pada peserta didik kelas X IPA SMAN 1 Batanghari sebanyak 33 peserta didik. Pada uji kali ini setiap responden diberi kuesioner isian yang telah disediakan. Data yang dihasilkan berupa data kuantitatif yaitu berupa nilai respon terhadap media pembelajaran blog yang di kembangkan. Hasil angket responden menujukan peredikat baik dengan skor rata-rata hasil rekapitulasi yaitu 4,197. 
Data respon peserta didik terhadap media blog disajikan pada Tabel 3

Tabel 3. Data Respon Peserta Didik Terhadap Media Blog

\begin{tabular}{cccc}
\hline No. & Uji Coba & Hasil respon & Kategori \\
$\mathbf{1}$ & Uji Coba Skala Kecil & 4,233 & Sangat Baik \\
$\mathbf{2}$ & Uji Coba Skala Besar & 4,197 & Baik \\
\hline
\end{tabular}

Berdasarkan data Tabel 2, kegitan uji coba yang telah dilakukan pada peserta didik kelas X IPA di SMAN 1 Batanghari dapat disimpulkan bahwa respon peserta didik terhadap media pembelajaran blog yang dikembangkan pada uji coba mengalami penurunan pada uji skala besar diakibatkan jumlah responden yang jauh berbeda, akan tetapi masih dalam kategori baik yang mendekati kategori sangat baik. Grafik hasil uji coba disajikan pada Gambar 1

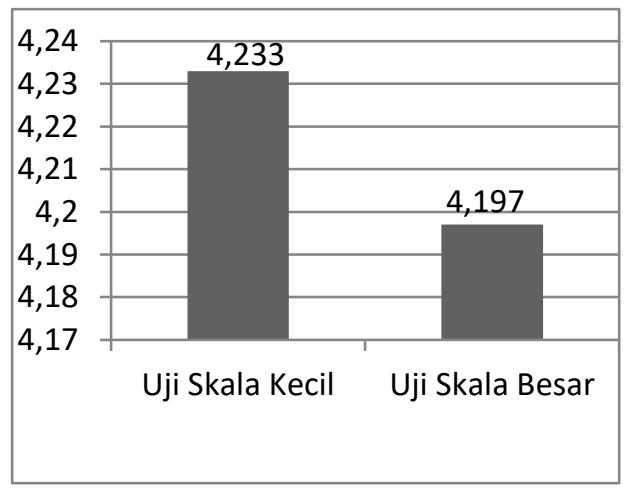

\section{Gambar 1. Respon Uji Skala Kecil dan Uji Skala Besar}

Berdasarkan hasil uji coba lapangan, diperoleh kelayakan masuk pada kriteria baik, sehingga penelitian dan pengembangan ini menarik digunakan sebagai alat bantu pembelajaran menggunakan komputer dan blog serta para pengguna bisa memperoleh ketrampilan dan pengetahuan tersendiri.

Pembelajaran menggunakan bantuan komputer untuk memperoleh pengetahuan dan keterampilan lebih mudah diperoleh dan dipelajari ulang sehingga siswa lebih mudah menyelesaikan masalah yang disajikan (Supriadi, 2015). Web dapat dimanfaatkan oleh guru matematika sebagai media alternatif penyampaian pengetahuan, media pembelajaran online, serta solusi untuk masalah kurangnya jam pembelajaran konvensional di kelas. Bahkan konten materi blog yang bagus, informatif, dan up to date akan menyebabkan blog dapat diakses bukan hanya siswa dari sekolah tempat guru tersebut mengajar akan tetapi dapat diakses oleh siswa dari sekolah lain yang berkunjung ke alamat blog tersebut. Penerapan media Web dalam pembelajaran matematika merupakan suatu hal yang positif bagi dunia pendidikan. Blog merupakan perpustakaan terbesar didunia, karena blog dapat berfungsi sebagai sumber belajar dan sekaligus media pembelajaran bagi peserta didik. 
Blog adalah bagian dari Web yang merupakan generasi kedua web. Sebuah blog adalah ruang berbasis web untuk menulis. Blog juga dapat digambarkan sebagai jurnal online di mana semua pengelola menulis dan mengedit informasi melalui browser web atau perangkat genggam dan sebagai salah satu cara yang efektif termasuk teknologi dalam bidang pendidikan, menyediakan partisipasi aktif dari seluruh siswa ke dalam lingkungan belajar melalui media yang berbeda.(Fajriah et al., 2017)

\section{SIMPULAN DAN SARAN}

Berdasarkan hasil penelitian dan pembahasan, validasi penilaian ahli materi diperoleh skor rata-rata 4,65 dengan kategori "Sangat Baik", validasi penilaian ahli media diperoleh skor rata-rata 4,35 dengan kategori "Sangat Baik", validasi penilaian ahli bahasa diperoleh skor rata-rata 4,5 dengan kategori "Sangat Baik". Selain itu dari hasil uji coba skala kecil respon peserta didik memperoleh skor 4,23 dengan kriteria "Sangat Baik", dan sedangkan pada uji coba skala besar respon peserta didik memperoleh skor rata-rata 4,19 yaitu pada kriteria "Baik". Dengan demikian dapat disimpulkan media pembelajaran berbantuan blog berada dalam kategori baik dan dapat digunakan maupun disebarluaskan dalam pembelajaran khususnya pada materi Trigonometri.

Berdasarkan kesimpulan penelitian ini, dapat diajukan beberapa saran bagi peneliti selanjutnya, diharapkan dapat mengembangkan media pembelajaran berbantuan blog pada materi lain ataupun dapat mengembangkan media pembelajaran lain untuk membantu dalam penyampaian materi trigonometri

\section{DAFTAR PUSTAKA}

Anggoro, B. S. (2015). Pengembangan Modul Matematika Dengan Strategi Problem Solving Untuk Mengukur Tingkat Kemampuan Berpikir Kreatif Matematis Siswa. Al-Jabar: Jurnal Pendidikan Matematika, 6(2), 27-39.

Arikunto, S. (1984). Dasar-Dasar Evaluasi Pendidikan. Yogyakarta: Bina Aksara.

Fajriah, N., Zulkardi, \& Siroj, R. A. (2017). Pengembangan Blog Untuk Mendukung Pembelajaran Pada Mata Kuliah Media Pembelajaran Matematika. Jurnal Edumath, 3(2), 89-100.

Fatmayanti, A. (2015). Pengembangan Media Blog Sebagai Sarana Informasi Untuk Meningkatkan Kemampuan Perencanaan Karir Di SMAN 1 Bulukumba. Jurnal Psikologi Pendidikan Dan Konseling, 1(2), 163-169.

Kustijono, R. (2012). Pembelajaran Berbasis Inquiry Melalui Pengembangan Blog Pembelajaran Fisika Dalam Mata Kuliah Multimedia. Jurnal Penelitian Fisika Dan Aplikasinya (JPFA), 2(2), 10-22.

Novalia, \& Syazali, M. (2014). Olah Data Penelitian Pendidikan. Bandar Lampung: Anugrah Utama Raharja (AURA).

Putra, F. G. (2016). Pengaruh Model Pembelajaran Reflektif dengan Pendekatan Matematika 
Realistik Bernuansa Keislaman terhadap Kemampuan Komunikasi Matematis. Al-Jabar: Jurnal Pendidikan Matematika, 7(2), 203-210.

Putra, F. G. (2017). Eksperimentasi Pendekatan Kontekstual Berbantuan Hands On Activity (HoA) Terhadap Kemampuan Pemecahan Masalah Matematik. Al-Jabar: Jurnal Pendidikan Matematika, 8(1), 73-80.

Ratnasari, A., \& Hamdan, Y. (2015). Penggunaan Blog Sebagai Media Penunjang Kompetensi Dosen. Jurnal Penelitian Komunikasi, 18(2), 89-100.

Rhamandica, C., Wonorahardjo, S., \& Arief, M. (2016). Pengaruh Pembelajaran Berbasis WEB Terhadap Hasil Belajar Mahasiswa Jurusan Kimia Pada Materi Kimia Inti Dengan Kemampuan Self Regulated Learning Berbeda. Jurnal Pendidikan : Teori, Penelitian, Dan Pengembangan, 1(10), 1891-1896.

Sugiyono. (2010). Metode Penelitian Kuantitatif, Kualitatif Dan $R \&$ D. Bandung: Alfabeta.

Sunismi, \& Fathani, A. H. (2017). Prototipe Model Collaborative Learning Matematika Melalui Media Blog dengan Interactive Digital Book Mata Kuliah Kalkulus II. Jurnal Fourier, 6(2), 69-83.

Supriadi, N. (2015). Pembelajaran Geometri Berbasis Geogebra Sebagai Upaya Meningkatkan Kemampuan Komunikasi Matematis Siswa Madrasah Tsanawiyah (MTs). Al-Jabar: Jurnal Pendidikan Matematika, 6(2), 99-109.

Weni, D. M., \& Isnani, G. (2016). Meningkatkan Hasil Belajar Siswa dengan Pengembangan Media Pembelajaran E-Learning Berbasis Blog. Jurnal Pendidikan Bisnis Dan Manajemen, 2(2), 114-123.

Wijayanti, A., \& Basyar, M. A. K. (2017). Pengembangan E-Portofolio Tematik-Terpadu Berbasis Web Blog untuk Menanamkan Karakter Kritis dan Kreatif melalui Pembelajaran IPA. Phenomenon : Jurnal Pendidikan MIPA, 7(1), 30-39. 